\title{
PENGARUH MODEL PEMBELAJARAN PROBLEM BASED LEARNING TERHADAP KEMAMPUAN PEMECAHAN MASALAH SISWA MTs MUSLIM CENDEKIA
}

\author{
Iran Sairan \\ MTs Muslim Cendekia Bengkulu \\ iransairan81@gmail.com
}

\begin{abstract}
In the context of mathematics learning, Problem Based Learning (PBL) is a mathematics learning strategy in the classroom with problem solving activities and provides more opportunities for students to think critically, creatively, reason, and communicate mathematically with their peers. The focus of this study was the ability to solve math problems. Based on the preliminary research the students experienced errors in re-checking the synchronization of resolution with the given problem. This research was quasi experiment research. Naturally selected subjects have been formed in one intact group (naturally formed intact group). Based on the research data obtained can be described in the problem solving ability of students whose learning applies PBL learning models higher than the problem solving abilities of students with conventional learning, where the average value of the posttest in the experimental class is 71.03. This study conclude that PBL learning models give positive effect on problem solving skills on the subject of the Linear Equation System of Two Variables in class VIII MTs Muslim Cendekia Bengkulu
\end{abstract}

Keywords:problem based learning, problem solving

\section{PENDAHULUAN}

Matematika merupakan suatu struktur aksiomatika yang mengedapkan deduktivitas sehingga objek matematika besifat abstrak, begitu pula matematika sekolah (Nugroho, Widada, \& Herawaty, 2019). Berdasarkan penelitian, Herawaty et al., (2019) menyatakan bahwa salah satu alternatif pembelajaran yang memberikan peluang tercapainya tujuan pembelajaran matematika adalah pembelajaran berbasismasalah. Problem-Based Learning merupakan pembelajaran yang diawali dengan menghadapkan siswa pada suatu masalah. Dalam konteks pembelajaran matematika PBL merupakan suatu strategi pembelajaran matematika di dalam kelas dengan aktivitas memecahkan masalah serta memberikan peluang lebih banyak pada siswa untuk berpikir kritis, kreatif, bernalar, dan berkomunikasi matematis dengan teman sebayanya. Dalam PBL siswa dituntut untuk menyelesaikan masalah yang sengaja diberikan oleh guru dengan berbekal pengetahuan, kemampuan, dan pengalaman yang dimiliki siswa.
Dalam sintaks model pembelajaran berbasis masalah, terdapat Fase Berpasangan. Pada fase ini siswa bersama teman sebangkunya diminta menemukan pemecahan masalah pada buku siswa ada dalam buku siswa. Siswa membandingkan pendapat/idenya dengan pendapat temannya. Guru meminta agar siswa bekerjasama secara berpasangan untuk melakukan negoisasi terhadap rencana pemecahan masalah yang telah mereka pikirkan sebelumnya. Guru sebagai fasilitator dan moderator mengarahkan siswa berdiskusi, membimbing siswa mengambil kesimpulan sampai pada rumusan konsep/prinsip berdasarkan matematika formal (idealisasi, abstraksi). Siswa diarahkan menarik kesimpulan dan membuat rangkuman tentang konsep/prinsip yang telah dipelajarinya. Dengan demikian, dalam proses problem based learning, siswa mengalami peningkatan dalam melakukan proses pemecahan masalah matematika Berdasarkan Japa (2008), bahwa setelah penerapan metode investigasi dalam pemecahan masalah matematika terbuka 
(salah satu problem based learning), siswa tampak aktif, kreatif, produktif, antusias, dan disiplin, sehingga kemampuan siswa dalam pemecahan masalah matematika meningkat. Hal ini dapat dilihat dari rerata persentase skor yang dicapai siswa pada saat tes akhir suatu siklus ke siklus berikutnya mengalami peningkatan. Persentase banyak siswa yang mencapai kategori baik atau sangat baik juga semakin meningkat. Berdasarkan kutipan di atas dapat disimpulkan bahwa penerapan problem based learning berpengaruh langsung terhadap kemampuan pemecahan masalah bagi siswa SMP/MTs. Berdasarkan fenomena di atas, peneliti tertarik untuk mengalisis apakah terdapat pengaruh penerapan model pembelajaran berbasis masalah (problem based learning) terhadap kemampuan pemecahan masalah matematika.

Kemampuan pemecahan masalah matematika menjadi fokus pembelajaran matematika. Fokus tersebut harus menjadi perhatian serius, karena berdasarkan pengalaman penulis selama hampir sepuluh tahun menjadi guru matematika tingkat SMP/MTs, siswa mengalami kesulitan dan kesalahan konsep/prinsip yang sangat berarti dalam pembelajaran matematika. Kesulitan dan kesalahan tersebut mulai dari kesulitan siswa memahami masalah, kesalahan siswa menyusun model matematika, kesalahan siswa menerapkan model metematika untuk menyesaikan masalah maupun kesalahan siswa memeriksa kembali sinkronisasi penyelesaian dengan masalah yang diberikan.

Berdasarkan penelitian awal penulis kepada siswa MTs Muslim Cendekia Bengkulu, ketikan siswa diminta untuk memecahkan masalah yang diberikan. Siswa mengalami kesulitan, bahkan hampir seluruh siswa tidak mampu menyelesaikan soal tersebut. Soal matematika tentang Pembelajaran Sistem Persamaan Linier Dua Variabel bagi siswa MTs Muslim Cendekia yang baru memulai pembelajaran materi tersebut. Sehingga soal tersebut menjadi masalah bagai siswa MTs Muslim Cendekia. Soal dimaksud adalah "Pada suatu hari Ani membeli 3 buah buku tulis dan 1 buah pensil dengan harga Rp 30.000,Karena merasa kurang, hari berikutnya Ani membeli lagi pensil dan buku yang sama sebanyak 2 buku tulis dan 2 pensil dengan harga juga Rp 30.000,- Tanpa mengetahui masing-masing harga buku dan pensil, dapatkah kamu menentukan barang mana yang lebih mahal? Jelaskan alasanmu!" Hasil penelitian awal penulis menunjukkan bahwa 86\% siswa mengalami kesulitan dalam memahami masalah, $100 \%$ siswa mengalami kesalahan dalam menyusun model matematika, $100 \%$ siswa mengalami kesalahan dalam menerapkan model matematika untuk menyesaikan masalah, dan $100 \%$ siswa mengalami kesalahan dalam memeriksa kembali sinkronisasi penyelesaian dengan masalah yang diberikan.

Hal ini menandakan bahwa dalam pembelajaran matematika bagi siswa tingkat Sekolah Menengah Pertama masih menemui kesulitan dan kesalahan yang berarti dalam memecahkan masalah matematika. Padahal pemecahan masalah adalah salah satu aspek kemampuan yang harus dicapai siswa dalam pembelajaran matematika. Dalam penelitian awal tersebut juga ditemukan kesulitan siswa dalam memahami konsep-konsep matematika, seperti siswa diminta untuk memahami konsep persegi dan persegi panjang. Ada $100 \%$ siswa mengalami miskonsepsi, yakni siswa tersebut menyatakan bahwa persegi bukanlah persegi panjang. Oleh karenanya kemampuan pemecahan masalah matematika masih menjadi problema dalam pembelajaran matematika. Dari permasalah yang ditemukan di lapangan dalam penelitian ini peneliti ingin menentukan besar pengaruh penerapan model pembelajaran berbasis masalah (problem based learning) terhadap kemampuan pemecahan masalah matematika.

Dengan demikian, dalam tulisan ini indikator kemampuan pemecahan masalah matematika adalah sebagai berikut:

(1) Memahami masalah, yaitu mengidentifikasi kecukupan data untuk menyelesaikan masalah sehingga memperoleh gambaran lengkap apa yang diketahui dan ditanyakan dalam masalah tersebut. 
(2) Merencanakan penyelesaian, yaitu menetapkan langkah-langkah penyelesaian, pemilihan konsep, persamaan dan teori yang sesuai untuk setiap langkah.

(3) Menjalankan rencana, yaitu menjalankan penyelesaian berdasarkan langkah-langkah yang telah dirancang dengan menggunakan konsep, persamaan serta teori yang dipilih.

(4) Melihat kembali apa yang telah dikerjakan yaitu tahap pemeriksaan, apakah langkah-langkah penyelesaian telah terealisasikan sesuai rencana sehingga dapat memeriksa kembali kebenaran jawaban yang pada akhirnya membuat kesimpulan akhir.

Menurut Arends (2001), PBL biasanya terdiridari 5 tahap utama yang dimulai dengan guru memperkenalkan siswa dengan suatu situasi masalah yang diakhiri dengan menyajikan dan analisis hasil kerja siswa. Jika jangkauan masalahnya sedang-sedang saja,kelima tahapan tersebut mungkin dapat diselesaikan dalam 2 sampai 3 kali pertemuan. Namun untuk masalah yang kompleks mungkin akan membutuhkan setahun penuh untuk menyelesaikannya. Kelima tahapan tersebut disajikan pada tabel berikut ini.

Tabel 1. Sintaks Model Problem Base Learning (Arends, 2001)

\begin{tabular}{|c|l|}
\hline TAHAP & \multicolumn{1}{|c|}{ TINGKAH LAKU GURU } \\
\hline $\begin{array}{c}\text { Tahap 1 } \\
\text { Orientasi siswa pada } \\
\text { masalah }\end{array}$ & $\begin{array}{l}\text { Guru menjelaskan tujuan pembelajaraan, menjelaskan } \\
\text { logistik yang dibutuhkan, memotivasi siswa terlibat pada } \\
\text { aktivitas pemecahan masalah yang } \\
\text { dipilihnya. }\end{array}$ \\
\hline $\begin{array}{c}\text { Tahap 2 } \\
\begin{array}{c}\text { Mengorganisasikan siswa } \\
\text { untuk belajar }\end{array}\end{array}$ & $\begin{array}{l}\text { Guru membantu siswa mendefinisikan dan } \\
\text { mengorganisasikan tugas belajar yang berhubungan } \\
\text { dengan msalah tersebut }\end{array}$ \\
\hline $\begin{array}{c}\text { Tahap 3 } \\
\begin{array}{c}\text { Membimbing penyelidikan } \\
\text { individual mampun } \\
\text { kelompok }\end{array}\end{array}$ & $\begin{array}{l}\text { Guru mendorong siswauntuk mengumpulkan informasi } \\
\text { yang sesuai, melaksanakan eksperimen, untuk } \\
\text { mendapatkan penjelasan dan pemecahan masalah }\end{array}$ \\
\hline $\begin{array}{c}\text { Tahap 4 } \\
\text { Mengembangakan dan }\end{array}$ & $\begin{array}{l}\text { Guru membantu siswa dalam merencanakan dan } \\
\text { penyiapan karya yang sesuai seperti laporan, video, dan } \\
\text { model dan membantu mereka untuk berbagi tugas dengan } \\
\text { temannya }\end{array}$ \\
\hline $\begin{array}{c}\text { Tahap 5 } \\
\text { Menganalisis dan } \\
\text { mengevaluasi proses } \\
\text { pemecahan masalah }\end{array}$ & $\begin{array}{l}\text { Guru membantu siswa untuk melakukan refleksi atau } \\
\text { evaluasi terhadap penyelidikan mereka dan proses yang } \\
\text { mereka gunakan. }\end{array}$ \\
\hline
\end{tabular}

Dalam konteks pembelajaran matematika, PBL merupakan suatu strategi pembelajaran matematika di dalam kelas dengan aktivitas memecahkan masalah serta memberikan peluang lebih banyak pada siswa untuk berpikir kritis, kreatif, bernalar, dan berkomunikasi matematis dengan teman sebayanya. Dalam PBL siswa dituntut untuk menyelesaikan masalah yang sengaja diberikan oleh guru dengan berbekal pengetahuan, kemampuan, dan pengalaman yang dimiliki siswa. Berdasarkan uraian di atas, menurut (Nugroho, 2017) dibutuhkan suatu model pembelajaran yang praktik dan mudah diterapkan. Model pembelajaran tersebut membantu guru dalam meningkatkan kinerjanya.

Dalam sintaks model pembelajaran berbasis masalah yang telah ditulis di atas, terutama pada Fase Berpasangan, bersama teman sebangkunya siswa diminta menemukan pemecahan masalah pada buku siswa ada dalam buku siswa. Siswa membandingkan pendapat/idenya dengan pendapat temannya. Guru meminta agar siswa bekerjasama secara berpasangan untuk melakukan negoisasi terhadap 
rencana pemecahan masalah yang telah mereka pikirkan sebelumnya. Guru sebagai fasilitator dan moderator mengarahkan siswa berdiskusi, membimbing siswa mengambil kesimpulan sampai pada rumusan konsep/prinsip berdasarkan matematika formal (idealisasi, abstraksi). Siswa diarahkan menarik kesimpulan dan membuat rangkuman tentang konsep/prinsip yang telah dipelajarinya. Dengan demikian, dalam proses problem based learning, siswa mengalami peningkatan dalam melakukan proses pemecahan masalah matematika.

\section{METODE}

Jenis penelitian ini dikategorikan ke dalam penelitian eksperimen semu (Quasi experiment). Subjek secara alami telah terbentuk dalam satu kelompok utuh (naturally formed intact group). Penelitian eksperimen memenuhi ciri-ciri penelitian yaitu: pemberian perlakuan (treatment) kepada subjek penelitian, pengamatan terhadap gejala yang muncul pada variabel terikat sebagai akibat pemberian perlakuan, pengendalian variabel lain yang bersama variabel perlakuan ikut berpengaruh terhadap variabel terikat. Sesuai dengan tempat ditemukannya masalah penelitian ini, penelitian eksperimen ini dilakukan di MTs Muslim Cendekia Kota Bengkulu. dengan populasi sebagai berikut:

Tabel 2. Populasi Penelitian

\begin{tabular}{|r|c|c|}
\hline No & Kelas & JumlahSiswa \\
\hline 1 & VIII A & 34 \\
\hline 2 & VIII B & 36 \\
\hline 3 & VIII C & 32 \\
\hline & Jumlah & 102 \\
\hline
\end{tabular}

Sampel dipilih dengan cluster random sampling secara intact group. Sampel yang terpilih memiliki sifat yang representatif dan dapat menggambarkan keseluruhan karakteristik dari populasi. Pemilihan sampel dilakukan kelas-kelas dalam populasi dipilih secara acak dengan syarat kelas dalam penelitian ini harus berdistribusi normal, memiliki variansi yang homogen, dan memiliki kesamaan rata-rata. Analisis dilakukan dengan menggunakan Software SPSS. Instrumen dalam penelitian ini menggunakan Pretest dan Posttest.

\section{HASIL PENELITIAN DAN PEMBAHASAN}

Data penelitian diperoleh dari tes pemecahan masalah yang diperoleh dari pretest dan posttest pada kelas eksperimen dan kelas kontrol. Kemudian dilanjutkan dengan pemberian perlakuan pada kelas eksperimen dengan menggunakan model pembelajaran Problem Based Learning (PBL), sedangkan untuk kelas kontrol pembelajaran berlangsung secara konvensional seperti yang biasa dilakukan oleh guru mata pelajaran matematika. Berikut ini deskripsi data yang diperoleh dari hasil pretest dan posttest pemecahan masalah pada kelas eksperimen dan kelas kontrol. 
Tabel 3. Deskripsi Statistik Kemampuan Pemecahan Masalah Kelas Eksperimen

\begin{tabular}{|c|c|c|}
\hline \multirow{2}{*}{ STATISTIK } & \multicolumn{2}{|c|}{ Kelas Eksperimen } \\
\cline { 2 - 3 } & Pretest & Postest \\
\hline Nilai Maximum & 30,00 & 95,00 \\
\hline Nilai Minimum & 18,00 & 51,00 \\
\hline Mean & 24,65 & 71,03 \\
\hline Median & 25,00 & 70,00 \\
\hline Modus & 22,00 & 60,00 \\
\hline Standar Deviasi & 3,75 & 12,16 \\
\hline
\end{tabular}

Dari tabel 3 dapat diketahui bahwa pada kelas eksperimen terjadi peningkatan nilai dari pretest ke posttest. Peningkatan nilai tersebut secara umum terjadi pada semua siswa. Hal ini terlihat dari peningkatan nilai terendah yang semula sebesar 18,00 pada pretest menjadi sebesar 51,00 pada posttest. Demikian pula nilai tertinggi yang semula
30,00 pada pretest menjadi 95,00 pada posttest. Dari nilai tertinggi pada pretest dan nilai terendah pada posttest, dapat disimpulkan bahwa semua siswa mengalami peningkatan nilai. Kemudian data pretest digolongkan berdasarkan kelas interval untuk dicari frekuensinya.

Tabel 4. Distribusi Frekuensi Pretest Pemecahan Masalah

Kelas Eksperimen

\begin{tabular}{|r|c|c|c|}
\hline No. & Interval & \multicolumn{2}{|c|}{ PemecahanMasalah } \\
\cline { 3 - 4 } & & $\begin{array}{c}\text { Frekuensi } \\
\text { (Pretest) }\end{array}$ & $\begin{array}{c}\% \\
\text { (Pretest) }\end{array}$ \\
\hline 1. & $18-20$ & 5 & 16,13 \\
\hline 2. & $21-23$ & 6 & 19,35 \\
\hline 3. & $24-26$ & 9 & 29,03 \\
\hline 4. & $27-29$ & 7 & 22,58 \\
\hline 5. & $30-32$ & 4 & 12,90 \\
\hline & JUMLAH & 31 & 100 \\
\hline
\end{tabular}

Dari tabel 4 diketahui bahwa 20 orang siswa dari 31 siswa hanya mampu mempunyai kemampuan pemecahan masalah sekitar 26\% dari kemampuan pemecahan masalah yang diujikan pada pretest. Hal ini menunjukkan bahwa kemampuan pemecahan masalah siswa masih rendah.

Tabel 5. Pengkategorian Posttest Kelas Eksperimen

\begin{tabular}{|c|c|c|c|c|}
\hline \multirow[b]{2}{*}{ No. } & \multirow[b]{2}{*}{ Interval } & \multirow[b]{2}{*}{ Kategori } & \multicolumn{2}{|c|}{ PemecahanMasalah } \\
\hline & & & $\begin{array}{c}\text { Frekuensi } \\
\text { (Posttest) }\end{array}$ & $\begin{array}{c}\% \\
\text { (Posttest) }\end{array}$ \\
\hline 1. & $\bar{X} \leq 68$ & Kurang & 11 & 35,48 \\
\hline 2. & $68<\bar{X}<78$ & Cukup & 10 & 32,26 \\
\hline 3. & $\bar{X} \geq 78$ & Baik & 10 & 32,26 \\
\hline & MLAH & & 31 & 100 \\
\hline
\end{tabular}


Dari tabel 5 dapat diketahui bahwa skor kategori kurang sebanyak 11 siswa atau sebesar 35,48\%, skor kategori cukup sebanyak 10 siswa atau sebesar 32,26\%, dan skor kategori baik sebanyak 10 siswa atau sebesar 32,26\%. Berdasarkan data penelitian yang diperoleh dapat dideskripsikan Kemampuan pemecahan masalah siswa yang pembelajarannya menerapkan model pembelajaran PBL lebih tinggi dari pada kemampuan pemecahan masalah siswa dengan pembelajaran. Dengan demikian model pembelajaran PBL memberikan pengaruh yang positif terhadap kemampuan pemecahan masalah pada pokok bahasan Sistem Persamaan Linier Dua Variabel di kelas VIII MTs Muslim Cendekia Bengkulu.

\section{SIMPULAN}

Berdasarkan dari hasil penelitian yang telah dilakukan maka dapat disimpulkan bahwa: Terdapat pengaruh model pembelajaran problem based learning (PBL) terhadap kemampuan pemecahan masalah pada materi lingkaran di kelas VIII MTs Muslim Cendekia Bengkulu. Kemampuan pemecahan masalah siswa yang pembelajarannya menerapkan model pembelajaran PBL lebih tinggi dari pada kemampuan pemecahan masalah siswa dengan pembelajaran konvensional, dimana nilai rata-rata postest pada kelas eksperimen diperoleh sebesar 71,03. Dengan demikian, model pembelajaran PBL berpengarhuh terhadap kemampuan pemecahan masalah pada pokok bahasan lingkarandi kelas VIII MTs Muslim Cendekia.

\section{REFERENSI}

Arends, R. I. (2001). Learning to Teach. New York: Mc Graw Hill Companies, Inc.

Herawaty, D., Widada, W., Umam, K., Nugroho, Z., Falaq, A., \& Anggoro, D. (2019). The Improvement of the Understanding of Mathematical Concepts through the Implementation of Realistic Mathematics Learning and Ethnomathematics. Advances in Social Science, Education and Humanities Research, Atlantis Press, 295(January). https://doi.org/10.2991/icetep18.2019 .6

Japa, I.G.N. (2008). PeningkatanKemampuanPemecah anMasalahMatematika Terbuka melaluiInvestigasibagiSiswa

Kelas V SD 4 Kaliuntu. JPPP: Lembaga PenelitianUndiksha, April 2008

Nugroho, K. U. Z. (2017). Pengaruh Penerapan E-Evaluation Dalam Pembelajaran Terhadap Kinerja Guru Matematika Sma Kota Bengkulu. Jurnal Pendidikan Matematika Raflesia, 2(2), 151154.

Nugroho, K. U. Z., Widada, W., \& Herawaty, D. (2019). Pemahaman Konsep Matematika melalui Media Youtube dengan Pendekatan Etnomatematika. Jurnal Pendidikan Matematika Raflesia, 04(01), 96-106. 